\title{
THE SELF-REPORTED PATENT QUALITY OF CHINESE FIRMS: MOTIVATION SOURCE AND TECHNOLOGY ACCUMULATION EFFECTS ANALYSIS
}

\author{
HAO MAO, LAUREN A. JOHNSTON and ZHIFENG YIN
}

\begin{abstract}
Enhanced innovation capacity has become imperative to China's growth and development. Patent quantity and quality indicators are benchmark measures of innovative capacity. This paper utilizes data from the 2013 Chinese Patent Survey to explore self-evaluated firm-level patent quality in China. Focus is placed on the effects of technological accumulation and also patent motivation on four multi-dimensional self-evaluation indices: technical quality, writing quality, right stability and market value. The results: (i) verify the proposal that in high patent intensity industries "strategic patent behavior will reduce patent quality"; (ii) suggest that reducing administrative-driven patent behaviors could improve patent quality; (iii) and find patent structure but not quantity to be positively correlated with patent quality. This serves to enrich understanding of China's patent system and the one-dimensional "inventive step" analysis deriving from analyses of European Patent Survey data.
\end{abstract}

technological accumulation

Classification codes: O31, O32, C25, C51, L00, L20 


\section{Introduction}

Innovation capacity has only recently become important to China's ongoing economic development, and is a cornerstone of the $12^{\text {th }}$ five-year plan (2012-2017). The potential for China to emerge as an important scientific nation was, however, earlier studied by Zhou and Leydesdorff (2006). Garnaut (2012) notes that within less than decades economic growth in China will derive from innovation that sits at the frontiers of world productivity (Garnaut, 2012: 457). Over years 2015-2019 China's economy is forecast to contribute $1.1 \%$ to global growth levels (IMF, 2014). Taken together this implies that China's innovation drive is now also important to global growth.

Patent quantity and quality indicators are benchmark measures of static and dynamic innovative capacity. In China the number of patent applications is growing explosively. In 2014 China's innovators applied for the highest number of patents worldwide, at 928,177 (WIPO, 2015) ${ }^{1}$. Rapid growth in China's patent application number has, however, generated institutional challenges for China's State Intellectual Property Office (SIPO) (eg. Yang, 2008; Liegsalz and Wagner, 2013) and also debate around the quality of those applications. This debate holds that compared to longstanding high patent filing countries such as the United States of America (USA), Germany and Japan, there is a large gap between patent number and quality in China's case. Patent quality is essential for the efficacy of the patent system, and also demonstrates relative national patent capacity. Moreover, low-quality patents also directly induce inefficiencies and frictions in the innovation system, thereby retarding rather than stimulating innovation (Sampat, 2005; Merges, 1999).

Patent quality is typically measured using objective indices (or administrative record of patents) which are those able to be directly compared, including indices of patent citation, patent duration, and number of claims. Subjective indices are by comparison based on self-reported patent quality evaluation. Importantly, there are valid reasons that objective and subjective indices of the same set of patents may not be

${ }^{1}$ http://ipstats.wipo.int/ipstatv2/index.htm?tab=patent 
consistent. In particular, this applies to the case of patents design to reach beyond traditional technology protection motivations and that are instead designed for reasons of strategic competition (Lamping et al, 2014). This is because these patents are often low in quality with respect to objective measures of patent quality such as patent writing and direct economic return, but are measured as of high quality within a patent portfolio (Harhoff et al, 2007). This increasingly complex set of valuation determinants make patent quality difficult to capture, and challenge the traditional reliance of the literature on objective indices.

Subjective indices offer a potential complement to objective indices in study of patent quality that warrant further exploration in light of the noted increasing diversity of patent motivation source. In this study, we evaluate Chinese patent quality through study of the following subjective (self-reported) patent quality indices: technical quality, writing quality, right stability and market value, using data from the 2013 China Patent Survey. In sum, we find that: i) self-reported quality measures are significantly correlated with hard data; ii) self-reported quality is negatively correlated with patent quantity but positively correlated with patent structure (as measured by invention patent share); and iii) self-reported quality is positively correlated with market-oriented patent motivation and negatively correlated with non-commercial patent motivation. Our results shed light on firm-level patent-seeking drivers in China, for example in having identifying a negative correlation between patent quality and politically incentivized patent filing motivations. This analysis extends the patent quality evaluation literature in formulating a use for a subjective measure of patent quality, in this case a firm-level patent set of data. This could offer a useful reference for further advancing understanding of variables associated with a successful patent system and patent system design (Banerjee and Kabiraj, 2011 ).

The rest of this paper is structured as follows: the second section introduces more of the related literature and our model; the third section describes the China Patent Survey of 2013 and the data we take from it; the final sector presents our empirical results; the final section presents our conclusion and policy implication. 


\section{Patent Quality Literature}

Generally speaking high quality patents should embody high quality legal and economic properties. The former however conveys no information about the expected economic value of the invention since patents of high legal quality are inventions that meeting a legal standard of novelty, inventiveness and utility (Palangkaraya et al, 2011). Burke and Reitzig (2007) propose that high quality patents should be embodied three characteristics: a high technological feature; high potential for economic return; and high stability. Patents with all of these characteristics are exposed to a low probability of becoming invalid. Of these dimensions, technical quality and right stability are the two characteristics roughly denoting a patent's "Inventive Step" (Harhoff et al, 2003; Reitzig, 2003; Lerner, 1994). Patent writing serves as the bridge between invention and market return, and which derives from the artisan work of both the patent applicant and the patent examiner (Mann and Underweiser, 2008; Sampat, 2005) and is in its own right an important element of patent quality.

An extensive body of literature uses objective patent measures to study patent quality, for example via an evaluation of market value and through patent maintenance length (e.g. Pakes and Schankerman, 1984; Zhang and Chen, 2012; Huang, 2012; Zhang et al, 2014); the number of patent families (Reitzig, 2002) and patent stability as measured by the timing a patent being challenged or subject to an objection request (Harhoff et al, 2003; Harhoff and Reitzig, 2004). This body of research in general finds patent quality to be correlated with high patent market value. A more nascent and complementary body of literature explores patent quality using subjective measures of patent quality. Most of this body of research is focused on market value determination. Examples include Gambardella et al (2008) who estimate patent value using the European survey of patentees; Palangkaraya et al (2011) who estimate the patent premium based on the Australian Inventor Survey. In this paper we add to the subjective indices literature through exploration of patent quality along various dimensions of selfreported data, and here applying this to the case of China and specifically data from the 2013 China Patent Survey. 


\subsection{Do technological accumulation and patent motivation respectively influence patent quality?}

We seek to study the effects of technology accumulation and patent motivation type on patent quality in the case of China. Since patents are the product of technology accumulation, productive effort in technology accumulation is expected to correlate highly with patent quality. Since technology accumulation is difficult to quantify, we adopt an input and output perspective approach as a method for empirically tracing "technology accumulation" effort.

In undertaking that task, we assume that R\&D input of patents is a precondition for the onward potential to secure (self-reported) high quality patents. In turn, we expect that a firm with high R\&D input in patents creation, measured linearly by cost, is more likely to report higher quality patents. Second, we expect that the volume of patents and their structure will also influence self-reported patent quality. The relationship between patent quantity and patent quality is nonetheless uncertain. On the one hand, a larger number of patents infers that a firm enjoys a bigger technology base, which in turn will create scale economies around each individual patent and also enhance evaluation options. On the other hand, if a firm pursues patent volume for its own sake, this may come at the expense of patent quality. Such an increase in the number of patents could for example decrease the average quality of these patents, and thus the overall patent quality evaluation would be diminished. To that end, a firm's patent structure, defined by the invention patent share (number of invention patents as a share of total patents) is expected to positively correlate with patent quality ${ }^{2}$. In sum, we predict that self-reported patent quality will be positively correlated with technology accumulation; and that selfreported patent quality on the other hand may be negatively correlated with patent accumulation and positively correlated with invention patent share.

\footnotetext{
${ }^{2}$ In China there are three types of patent filings: invention, utility model and design patents. Among these, only the invention patent must be substantially examined and pass a test of usefulness, novelty and nonobviousness to be granted. Accordingly, the invention patent is widely recognized as being better in quality than that of the utility model and design patent. Therefore, in the case of Chinese patent data, we expect that the share of invention patents is positively correlated with high patent quality.
} 
Unlike in the past, the drivers of patent applications in recent decades increasingly go beyond traditional patent concerns of protecting technology and promoting license and transfer. Strategic use of patents arises where a patent is not intended for direct application or to be otherwise commercialized. Examples include that patents are now frequently used as a strategic tool to block competitors, for bargaining purposes, to prevent litigation and to enhance reputation (Harabi, 1995; Blind et al, 2006). Since this patent application strategy is defensive, and the patent contents are of indirect importance, this may reduce average patent quality. Following Harhoff et al (2007) and Lemley and Shapiro (2005) we thus argue that patent motivation could significantly influence patent quality.

Specifically, we predict a correlation between share of strategic patent motivation (or not based on patent commercialization) and lower patent quality. In other words, that the strategic use of patents will decrease patent quality. We also however, recognize that strategic use of patents could improve the patent right stability of other patents held by a firm. This is due to the fact that firms using a patent as a tool against litigation or competition treat such patents as a bargaining tool, which can serve to increase the stability of an individual patent within the patent portfolio. Since patents of no direct intended use are generally lower in quality than those filed with direct commercialization intent, the relationship between strategic use of a patent and patent quality in terms of right stability is uncertain.

Unlike strategic patent motivation, which is now ubiquitous across countries, an additional patent motivation is comparatively unique to the case of China. This relates to the extensive set of state policies and incentives that are designed to underpin the national drive to become an innovative economy. China's government offers various kinds of policies in support of domestic firms instigating patent creation and commercialization. For example, subsidies are allocated to firms toward generating content and toward applying for patents. Tax deductions are also available for high-tech (innovative) firms, etc. Such subsidies intend to enhance firm patent activity, but might also have an unintended consequence of distorting firm patent behavior and thus also patent quality. For instance, some firms applying for patents may not actually be attempting to protect 
an invention or defend against litigation, but could merely be rent-seeking by seeking access to subsidies or through currying political favor. And these interests are contemporarily directly better served by firms carrying the classification of a high-tech firm in China. We call patent-applying firms "policy-driven firms". Firms with a patent activity that in contrast is mainly driven by market incentives (for example, protecting the technology, market expansion, etc.) are herein called "market-driven firms". We predict that market-driven firms will report a higher-level of patent quality compared to policydriven firms.

To sum up, we use unique survey data on self-reported patent quality evaluation from China to test the hypothesis that self-reported patent quality is attached to firm patent motivation. We predict that self-reported firm-level patent quality will be negatively correlated with non-commercialization motives, and that self-reported patent quality will be positively correlated with market-oriented motivation. All references to patent quality infer the self-reported data collection definition described herein.

\section{Empirical Analysis}

\subsection{The Basic Model}

Our data comprises an ordinal ranking of patent quality scored using whole numbers between 1 and 5, with 5 reflecting the highest possible measure of quality and 1 of low quality. The characteristics of our data make use of a basic ordered Probit model appropriate for this analysis (Cameron and Thrived, 2005; Long and Freese, 2006). In turn, the basic model specification is:

$$
y^{*}=\mathbf{x} \beta+\varepsilon
$$

where $\mathrm{y}^{*}$ is the potential dependent variable; $\mathbf{x}$ is a vector of independent variables, and $\varepsilon$ is an error term with characteristics following a standard normal distribution. There are 4 threshold values $\mathrm{a}_{1}, \mathrm{a}_{2}, \mathrm{a}_{3}, \mathrm{a}_{4}$. We assume $\mathrm{a}_{1}<\mathrm{a}_{2}<\mathrm{a}_{3}<\mathrm{a}_{4}$, and so

giving us the following definitions: y equals 1 when $y^{*}$ is smaller than or equal to $a_{1} ; y$ equal to $i+1(i=1,2,3)$ when $y^{*}$ is larger than $a_{i}$ but smaller than $a_{i+1}$; and $y$ is equal to 5 
when $\mathrm{y}^{*}$ is larger than $\mathrm{a}_{4}$. With y representing self-reported patent quality (scored as a whole number between 1 and 5) the following identities hold:

$$
\begin{aligned}
& \mathrm{p}(\mathrm{y}=1 \mid \mathrm{x})=\mathrm{p}\left(\mathrm{y}^{*} \mathrm{y}(1 \mid \mathrm{x})=\Phi\left(\mathrm{a}_{1}-\mathrm{x} \beta\right)\right. \\
& \mathrm{p}(\mathrm{y}=\mathrm{i}+1 \mid \mathrm{x})=\mathrm{p}\left(\mathrm{a}_{\mathrm{i}}<\mathrm{y}^{*} \leqslant \mathrm{a}_{\mathrm{i}+1} \mid \mathrm{x}\right)=\Phi\left(\mathrm{a}_{\mathrm{i}+1}-\mathrm{x} \beta\right)-\Phi\left(\mathrm{a}_{\mathrm{i}}-\mathrm{x} \beta\right) \mathrm{i}=1,2,3 \\
& \mathrm{p}(\mathrm{y}=5 \mid \mathrm{x})=\mathrm{p}\left(\mathrm{y}^{*}>\mathrm{a}_{4} \mid \mathrm{x}\right)=1-\Phi\left(\mathrm{a}_{4}-\mathrm{x} \beta\right)
\end{aligned}
$$

The key independent variables include those defining technology accumulation and patent motivations. These are elaborated in the next section. We control for other variables expected to influence patent quality also, including location, ownership, size and various kinds of qualification status variables. These are also elaborated in the next section.

\subsection{Data and Variables}

Data for this study derives from the 2013 China Patent Survey, which was conducted by the State Intellectual Property Office (SIPO). The Survey was first undertaken in 2008, since which it has been conducted annually. The Survey adopts a probability proportionate to size sampling (PPS) approach meaning in other words that cities with more patent grants will be surveyed more than others. Data in any given survey is derived from a sample of the previous year's patents. By these standards, the 2013 sample included 65 cities within 26 provinces, provincial-level municipalities and autonomous regions. Surveyed patents are from the sample of those patents awarded in 2012. The sample specifically included 9,161 firms and 22,615 patents owners. The response rate was $87.7 \%$ making the sample size large enough for our analysis.

This study uses firm-level (and not patent-level) data. A firm can have many patents and each of which by definition varies uniquely. In our data, the firms report the average characteristics of the patents they hold. Questions in the survey ask firms to evaluate the quality of their patents. The dimensions of patent quality upon which evaluation is sought include overall quality, technical quality, writing quality, right stability and market value. Following Fowler (1995) the survey establishes five options for the self-reported value: "low", "relatively low", "moderate", "relatively high" and 
"high", and a parallel ranking value of 1 through to 5. This provides our ordinal rank data for general quality value (GEN) alongside that of the four sub-indices: technical quality (TEC), writing quality (WRI), right stability (STA) and market value (MAR). This provides a comprehensive structural measure of firm-level patent quality.

We use this data to construct three measures of technology accumulation. The first is patent related $R \& D$ cost (denoted as $R \& D$ cost). In the China Patent Survey, firms were asked about the estimated $R \& D$ costs for patent creation ${ }^{3}$. We calculated the median of the $R \& D$ cost of surveyed firms, and thereafter allocated firms a binary indicator as follows: 1 where R\&D cost was higher than or equal to the median, or 0 where $R \& D$ cost was lower than the median. To examine the impact on patent quality of a firm's R\&D investment, using data on average $R \& D$ cost of patent compares favourably with using overall firm R\&D expenditure since investment in $R \& D$ funds per patent output represents a real investment in the patent production process, to which the quality of patents is closely linked. On the contrary, realization of a patent is only part of outcome of overall $R \& D$ expenditure, since a share of $R \& D$ funding will be allocated to producing trade secrets, technical standards, training, and so on. We therefore select firm patentrelated $R \& D$ costs to capture actual patent production-related $R \& D$ funding.

Two additional measures capture patent quantity and patent structure. For the former, we construct a variable, totpat, to measure the total valid patent filings of a firm up until 2012, and a second variable, invshar, which refers to a firm's share of invention patents as a proportion of their total patents. The data used to construct totpat and invshar come from China Patent Database.

Alongside these measures of patent quantity and quality, we construct measures of patent motivation. First, we construct mar_renew to capture market-driven firm patent renewal behavior. The data for this is derived from the Survey question "Why do you renew your patent?"4, the answer to which respondents selected from the list of presented

\footnotetext{
${ }^{3}$ Their response was limited to a choice of one of eight cost ranges: 50,000 yuan and below, 50,000-100,000 (including 100,000 ) yuan, 100,000-500,000 (including 500,000) yuan, 500,000-1 million (including 1 million) yuan, 1 million-5 million (including 5 million) yuan, 5 million-10 million (including 10 million) yuan, 10 million-50 million (including 50 million) yuan or 50 million yuan above.

${ }^{4}$ In answering this question, surveyed firms were asked to choose from multiple-choice answers comprising the details of the questionnaire.
} 
choices. The answer is interpreted as market-driven if the reply includes any one of the following "earn profit and reduce cost", "use patent as an exchange asset or bargaining chip" and to "protect the technology". We also define a variable, fss_app, to capture firm patent strategy. This measure reflects non-commercialization motivation, information about which comes from the Survey question "Why did you apply for a patent/s?" Similarly, for this question, surveyed firms should select answers from the choices presented in the questionnaire. Response options include traditional motivations such as "to increase market share" and "to prevent imitation", as well as additional contemporary strategic and non-commercial motivations including "to block competitors", "to establish a product standard", "to accumulate technology stock", "to improve the firm's image (as an innovator)". We then calculate the share of these non-commercial motivations among the total listed motivations chosen by firms.

We also include key control variables, such as IP department settings (ip_dep), firm ownership structure (own), firm size (size) and various qualification status variables. Table 1 shows that all such variables fall in the reasonable range. We also calculate the correlation coefficients of the core explanatory variables, finding that these coefficients are all smaller than 0.3 . This means our regression analysis has a relatively small risk of suffering complications arising due to multi-collinearity.

Please insert table 1 about here

Table 2 presents the descriptive statistics for the self-reported patent quality data used in this analysis. From this we can learn that firms in general are optimistic about their patent quality: few firms claim to hold patents "low" in quality; nearly half of firms report their patent quality level to be "moderate"; nearly 35\% of firms rank their patent quality as "relatively high" and almost 7\% of firms rate their patent quality as "high". For the sub-indices, the average rank for technical quality and right stability are higher than that of overall patent quality. The rank for market value is however, relatively low. Nearly $30 \%$ of firms report having a "relatively high" market value, which is about $5 \%$ lower than that of other indices. The share of firms claiming a "low" patent market value is evidently greater than those claiming so for the other three quality indices. We see also that the share of firms claiming that the writing quality of their patents is "high" is the 
lowest among the four quality indices. In sum, among surveyed firms the relatively low quality of market value and writing quality are the key patent issues.

Please insert table 2 about here

To explore the validity of our self-assessment data, we study the consistency between self-reported quality data and more traditional objective (hard) measures patent quality. Hard data availability includes the number of patent filing claims, the number of pages of applicant filings and the duration of granted patents. The three hard data points are sourced from China Patent Database 5 . The number of claims and the pages of a patent application file are key structural elements of patent drafting, and are thus expected to correlate highly with writing quality and technical quality (Reitzig, 2002). The duration of a patent is expected to be positively correlated with self-reported patent quality. Since renewal behavior serves as a trade-off between the benefit derived from a valid patent and the cost of renewing the patent, long patent life is a useful measure of (high) patent quality.

Please insert table 3 about here

Table 3 lists the pairwise correlation coefficients for all patent indices used herein. These results show that overall patent quality is highly correlated with the sub-indices. The quality of market value and the technical quality indices demonstrate the highest correlation ( 0.78 and 0.77 respectively), indicating that surveyed firms put greater positive weight on market value and technical quality of their patents. These sub-indices correlation coefficients are also all significant at the 0.05 significance level, implying that

\footnotetext{
${ }^{5}$ We get the patent information via the patent application id and firm's organization code.
} 
the sub-indices are mutually respectively consistent and complementary, and thus are conservator comprehensively measure overall patent quality.

Next we test the consistency between the self-reported indices and the standard objective patent quality indices. For reasons elaborated in the literature (Reitzig, 2003; Hall and Harhoff, 2012) and also due to data availability we focus on objective indices including number of claims (CLAIM), number of pages of application file (PAGE) and patent duration (Duration) ${ }^{6}$. These results are presented in Table 4.

Please insert Table 4 about here

Data presented in Table 4 reveals self-reported patent measures to be consistently positively correlated with equivalent hard data. Among the variables listed, the correlation coefficients between each of CLAIM and PAGE and technical quality and writing quality are comparatively high. Duration is more highly correlated with right stability. A number of factors may however, explain the lower correlation coefficient levels in general. First, competition among firms in the era of the knowledge economy has resulted in a more competitive intellectual property rights environment. This has inspired patents to be newly frequently used mainly as a defense or attack tools. Such strategic use leads to divergence of subjective and objective patent quality judgments (Lamping et al., 2014). This itself relates to the fact that the individual quality of a particular individual patent may be low, even approaching zero, but in the context of an entire patent portfolio, the same independently worthless patent may serve to dramatically increase the overall value of other patents, and thus becomes of a new derived value. In other words, a patent characterized of low objective value may have a

\footnotetext{
${ }^{6}$ CLAIM, PAGE, DURATION are defined as binary indicators carrying a 0 or 1 value. For CLAIM, we first collect claim information for each valid patent from 1993 until till 2012 from the surveyed firm data in SIPO's valid patent database. We then calculate the average number of claims per firm, followed by the median claim number among surveyed firms. CLAIM holds the value of 1 if a firm's average claim level is larger than the median value, and 0 otherwise. We construct variable PAGE in a similar way. For DURATION, we first collect duration information for each invalid patent up to 2013 among surveyed firms from the SIPO's invalid patent database and then calculate the average duration for each firm. We then calculate the median duration value among the surveyed firms. In our empirical analysis, we define DURATION as 1 if a firm's average duration is above the median value, and 0 otherwise.
} 
high subjective value where and for example it serves a defensive market purpose that enhances firm bargaining power or otherwise protects core patents (Harhoff et al., 2007).

A second reason that objective and subjective measures of the same patent's quality may diverge relates to the fact that any obtainable hard data typically reflects only a very specific dimension of patent quality, such as the average number of patent claims or the number of pages of in application file. The case of patent writing however, also includes decisions such as whether to commission a professional third-party, standard descriptions of the main technical issues of the patent (Reitzig, 2004), and so on. Such a specific indicator of quality dimension is different to the more holistic measure of patent quality level that is captured by self-reported data. Similarly, objective patent quality evaluation measures do not necessarily fully account for the market value of the patents. From the perspective of the firm's own needs accounting for example it may insufficient capture the impact of capital markets in realizing the value of a patent. We believe that these factors combine to explain the lower correlation between the subjective and objective quality indicators, and draw attention also to the potential independent value of subject patent data ${ }^{7}$.

\subsection{Basic Empirical Results}

As noted in section 3.1, we select an ordered Probit model regression analysis to empirically study the effect of technology accumulation and patent motivation on patent quality. Table 5 outlines our results. Column one shows that firm's patent related research and development (R\&D) costs is positively correlated with self-reported patent quality, and this is significant at the 0.01 significance level. This probably follows from the fact that R\&D is usually a key precondition for high quality patents, and from which it could be inferred that increasing $\mathrm{R} \& \mathrm{D}$ investment in patent creation is a valid instrument toward enhancing patent quality. In addition, high R\&D investment constitutes a useful signal of a good patent. A good patent (from an economic standpoint) is an invention that

\footnotetext{
${ }^{7}$ In Peston et al. (2015), the correlation between measured and self-reported BMI data reached 0.96. One important reason for this high correlation is that the measurement is of a very specific indicator based on height and weight data points - two points that stay relative constant, or change slowly and within a relatively limited range, over a lifetime. This case is thus very different from the self-reporting of patent quality in this study.
} 
would not have been created in the absence of the potential of realizing the patent. In other words, the expectation of earning monopoly profits from selling the patented invention is sufficient at the margin to provide an incentive for the firm to invest ex ante. If the patent was not required to instigate this investment, there is no need for a patent.

Data in column two (Table 5) outlays the results from examining the correlation between the number of patents, the share of invention patents and patent quality. There are two important findings: first, the total number of patents is negatively correlated with evaluation of patent quality; secondly, invention patent share is positively correlated with patent quality evaluation. The former may be understood through the fact that some patents are of low quality when firms are in a period of patent application expansion, thus dragging down average quality. The latter suggests that improvement in the patent structure can promote patent quality, and raises the concern that the contemporary explosion of patent applications in China could be taking place inefficiently. The importance of quantity management and patent structure management as part of a process of patent quality improvement are herein highlighted.

Results in the third column draw attention to the relationship between patent motivation and patent quality. Market-driven firms tend toward higher self-evaluated patent quality than firms whose patent renewal behavior is not market-driven. Firms whose patent renewal behavior is otherwise and more specifically driven to "meet a qualification goal", "obtain industry subsidies" and "reach patent quantity targets" (behaviors defined as policy-driven) self-evaluate their patent quality less favorably than firms that renew patents for reasons of "increased revenue, reduced cost" and "protecting technology"(behaviors defined as market-driven). This provides evidence for static criticism of China's patent subsidy policy in that it is possible that firms will be motivated to invest in low quality patent-seeking behaviour in order to enjoy public subsidies. Low quality patents may receive less firm prioritization if instead there was no subsidy attached to them.

Column four presents results on the relationship between the intensity of noncommercial motivations and self-evaluated patent quality. The results suggest the intensity of non-commercial motivations is negatively associated with our measure of 
patent quality. This finding is consistent with Harhoff et al (2007) who propose that the strategic use of patents on average decreases the quality of patents. A possible interpretation is that in comparison to a direct commercial inventive patent motivation a non-commercial motivation has less of a quality filter, including for example where firms seek a patent for the purpose of defense or competition blocking. Defensive patents are usually relatively low in quality compared to those motivated by direct commercial incentive. In the first instance, these types of patent motivations thus serve the lower the overall level of patent quality. Whether or not their presence more dynamically enhances the quality of existing high-quality patents as well as better incentivizes research toward high quality invention patents is not understood from this study.

The fifth column reflects a joint test of the determinants, the results of which reveal the impact of technology accumulation and patent motivation on patent quality to be robust as compared to the individual tests. This shows both the technology accumulation and patent motivation are important forces determining the patent quality of the studied firms. The economic explanation is likely to be similar to that of each separate case and as earlier elaborated. It is worth also mentioning that the additional control variables are significantly correlated with patent quality. For example, both IP recognized firms and high-tech firms report relatively higher quality patents than their counterparts. Central government affiliated firms and listed firms, however, do not report higher patent quality than their counterparts. This implies that there is still space for patent quality improvement for these firms.

Please insert table 5 about here

Now we extend our analysis by testing for effects within the four sub-indices. Columns 1-4 of Table 6 list the results for those sub-indices, respectively technical quality, writing quality, right stability and market value. We find firstly that a positive relationship exists between $\mathrm{R} \& \mathrm{D}$ cost and patent quality across the four sub-indices. Second, we identify a negative relationship between patent quantity and patent quality 
that is statistically significant in the cases of technical quality, right stability and market value, but not writing quality. The latter may relate to the scale economy attached to learning writing skills. In this case accumulated application experience could enhance firm's patent drafting skills, reflecting the 'learning by doing' principle articulated by Arrow (1971), related to which is that experienced patient lawyers are also few in China. Their short supply and the nascent innovation phase of many patent-seeking firms may mean that such firms are choosing to allocate their innovation budgets to invention ahead of expert patent writing costs, at this stage.

Please insert table 6 about here

Third, across all four sub-indices a positive relationship is found between invention patent share and patent quality, and also between market driven motivation and patent quality. Finally, a negative relationship is found between non-commercial motivation intensity and patent quality, but this is only significant in the cases of technical quality and market value, but not writing quality or right stability. A noncommercial motive always contains an element of using a patent as a tool of defense or of bargaining power. Although patents for defensive purposes may be lower in technical quality and market value, and thus may reduce right stability, integration of such patents into the entire patent portfolio can, however, enhance patent right stability. This makes the relationship between non-commercial motive and right stability complex to ascertain.

\subsection{Robustness Tests and Discussions}

As previously argued, we have highlighted a few advantages to self-reported patent quality indicators. First, the particular self-reported patent quality data used in the

present study is evaluated by firms along the four dimensions: technical quality, writing quality, right stability and market value. All related data is available, and these factors are used as a comprehensive measure of patent quality; Second, self-reported patent quality indicators may selectively offer a more comprehensive reflection of patent quality than the objective indicators. For example, when a patent becomes part a patent portfolio for 
the purpose of deployment as a negotiating tool and/or as a way to protect an expected high-value future market, the value of the patent is difficult to characterize through objective indicators. In such cases, a subjective evaluation of the patent by the firm may offer important additional information that current objective patent metrics do not yet capture.

On the other hand, Peston et al. (2015) demonstrate that use of self-reported data with categorical characteristics will result in measurement error and missing information problem, and thus influence the accuracy of resulting estimation. The present study is based on self-reported patent quality data and may thus also be exposed to such issues. On this basis we perfect some robustness tests using additional objective measures of patent quality. Specifically, three objective patent quality indicators are used for these tests: the average number of patent claims (CLAIM); average number of pages in the application file (PAGE); and the average duration of patent (DURATION). The results of tests show that firm $R \& D$ cost is significantly positive correlated with the average number of patent claims and also the number of pages in application file. In addition, patent quantity is significant positively correlated with the average number of claims, the number of pages in the application file and the duration of patent. There is moreover a positive correlation between invention patent share, the average number of patent claims, the number of pages in the application file, and duration of patent. Non-commercial motivation intensity is significantly negatively correlated with the number of patent claims, the number of pages in the application file and patent duration. These are results that are consistent with the findings using self-reported data8.

Secondly, we perform robustness testing using continuous instead of binary hard data (i.e., CLAIM, PAGE and DURATION). That testing finds a significant positive correlation between R\&D costs and the average number of pages in the application file; a significant and positive correlation between the number of patents, the average number of patent claims and the number of pages in the application file; a significant positive correlation between the share of invention patents, the average number of claims, and patent duration was identified; and finally also identifies a positive correlation between market driven motivations and the average number of patent claims. Non-commercial 
motivation intensity meantime is significantly negatively correlated with the average number of claims, the pages in application file and patent duration. These findings are broadly consistent with the findings of this study using self-reported (subjective) data ${ }^{8}$.

Further robustness tests are undertaken to better understand our indicator of patent related R\&D cost. The 2013 Patent Survey asked firms for overall R\&D spending in 2012. Here we use $2012 R \& D$ funding in place of the previous patent $R \& D$ cost. That is, using this alternative measure of $R \& D$ expenditure we re-test the impact of technology accumulation and patent motivation on patent quality. To avoid the effect of extreme values, we however, removed $\mathrm{R} \& \mathrm{D}$ spending of less than $1 \%$ or more than $99 \%$ of the observed value. For data smoothness, we used the natural logarithm of R\&D spending. The results illustrate that there is a significant positive correlation between R\&D investment, overall patent quality and the stability of patent rights. Patent quantity is significant negatively correlated with overall quality and is mainly related to the negative correlation between technical quality, stability of patent rights and market value. There is a significant positive correlation between the share of invention patents and each dimension of patent quality. At the same time, market-oriented motivation is significantly positively correlated with each dimension of patent quality; the non-commercial motivation intensity and the overall patent quality are negatively correlated, which also highlights the negative correlation between non-commercial motivation intensity and technical quality and market value ${ }^{9}$. These results suggest that the basic conclusions of this study are robust.

We finally also undertake a further robustness test in controlling for industry fixed effects. Since firm-level industry data is not available from the survey, the previous regressions did not control for industry fixed effects, which will influence the accuracy of estimation. For this robustness check we matched the surveyed firms with a large and medium firm dataset (from National Bureau of Statistics (NBS)). According to the matching of these classifications with each firm's organization code, each firm data point

\footnotetext{
${ }^{8}$ Not listed in the paper and are available up request.

${ }^{9}$ Not listed in the paper and are available up request.
} 
then also has the associated allocated industry code ${ }^{10}$. In line with Graevenitz et al (2011) we propose that firm strategy will be heterogeneous within industries characterized by varying patent intensity between firms. Especially in a patent thicket industry (characterized by a high density of over-lapping patents that necessitates intimate knowledge of for new related patents to be able to be filed), a firm's patent strategy may be unique and the effects of technology accumulation and patent motivation on patent quality may thus be similarly unique.

Please insert table 7 about here

Following SIPO (2013) ${ }^{11}$ we obtain the industrial patent intensity for each 4-digit manufacturing industry and divide the sample into two groups. Group one constitutes firms whose industrial patent intensity are smaller than the median value (denoted as the low patent intensity industry group); the remaining firms fall within the second group (high patent intensity industry group). We re-estimate model for each of the low patent intensity industry and high patent intensity industry groups separately, and controlling for the industry fixed effects. The results in Table 7 firstly imply that there is a positive relationship between R\&D cost and patent quality (both overall and for each of the subindices) in both high- and low-patent intensity industry groups.

Second, we find that the relationship between patent quantity and patent quality differs between industry groups. In the low-patent intensity industries, a negative relationship between patent quantity and overall patent quality is not statistically significant, which is different from the results of the whole sample. However, patent quantity is positively associated with writing quality, suggesting economies of scale in patent drafting or for example that there may exist a patent quantity threshold or critical point that must be crossed before a firm will also invest in the art of patent writing. In the

\footnotetext{
${ }^{10}$ Note that only the firms with annual sale larger than (or equal to) 20 million RMB are surveyed in the NBS dataset, meaning we lose almost half of study sample after matching.

${ }^{11}$ Calculate the five year average granted patent amount-employees ratio(piece/10thousand).
} 
case of high-patent intensity industries, we also identify a negative relationship between patent quantity and quality in most cases, implying that patent expansion is accompanied by a worsened average patent quality. This is especially true in the case of patent thicketed industries.

Third, this part of our analysis finds a positive effect on patent quality of invention patent share, and also for market driven motivation, which a real most found in high and low patent intensity industries; Finally, we find the adverse effect of noncommercial patent motivation intensity to be most prominently reflected in the highpatent intensity industry group and in the dimension of market value. A potential explanation is that firms in patent thicketed industries are more likely to strategically use patents that are directly low in market value as a tool for blocking competitors and as bargaining chips. This type of patent strategy may mean such firms apply for proportionately more patents for a defense purpose, and thereby reducing the average market value of their patents.

\section{Conclusions and Policy implication}

Utilizing data from the 2013 China Patent Survey this paper has empirically examined the effects of technology accumulation and patent motivation on firm-level self-reported patent quality in China. First, we explored the relationship between overall patent quality and four sub-indices - technical quality, writing quality, right stability and market value. Then we studied the level of consistency between self-reported patent quality indices and an assumed parallel set of hard data indices that are relatively widely used in literature. Finally, we tested the effects of technology accumulation (R\&D cost, patent quantity and patent structure) and market motivation source (market-driven patent behavior and non-commercial motivations) on patent quality.

In concluding, firstly we have established a means of utilizing self-reported patent quality data. For example, we specifically identified that the overall patent quality index 
and the sub-indices are internally compatible. The four sub-indices are also highly correlated with overall patent quality, especially in the case of market value and technical quality. In addition, self-reported quality measures are found to be significantly correlated with hard data: structurally, the number of patent claims and application pages are relatively highly correlated with technical quality and writing quality; patent duration is relatively highly correlated with patent right stability.

Secondly, we identified positive effects for technology accumulation on patent quality. Our empirical findings point to innovation efforts being positively correlated with patent quality. This implies that R\&D input is the driving force for improving patent quality. We also identified a negative relationship between patent quantity and patent quality, especially in high-patent intensity industries. The share of invention patents is also positively related to patent quality in most cases.

Third, we reach some important conclusions around the effects of patent motivation. For example, our results confirm that firms whose renewal behaviors are reported as being market-driven on average report a higher evaluation of patent quality. In contrast, firms whose patent renewal behavior is driven by "meeting a qualification", "obtaining subsidies" or "completing a patent task" self-evaluate a lower level of patent quality. We finally also identify that non-commercial intensity is associated with lower levels of self-evaluated patent quality, especially for the dimension of market value and for firms in high-patent intensity industries.

A few structural limitations of the China Patent survey also highlight the need for improved data collection and more related research. First, the design of China's patent survey makes it is difficult to study change over time. This owes to the fact that each survey takes it sample from last year's granted patent, and not from a consistent sample. As the years of the survey accumulate, it may be possible to study a particular set of patent-active firms over time. An additional challenge with the structural set up of the survey is that propensity to answer and perception of patent quality may itself be a function of patent quality, which would bias the results. It is similarly possible that firms in high-patent intensity industries happen also to be those in industries that are more market-driven. Finally, as Li (2009) highlighted, China's innovative capacity varies 
immensely between provinces. How and whether or not this affects the results of firm self-reported data also needs attending to.

These limitations given, we draw several conclusions from our findings. Firstly, greater attention should be paid to the adverse effects of selective patent strategies on patent quality, both in pursuit of higher quality innovation and in terms of the reliability of standard objective patent measurement of patient quality. Lamping et al (2014) argued that with the explosion of patents and the emergence of patent thicketed industries, firm patent strategies have extended far beyond traditional concerns, presenting a challenge to patent quality and the spirit of the patent system itself. In the case of China, our results identify that non-commercial motivation (strategy) intensity is negatively associated with firms' patent market value. This echoes Harhoff et al (2007) in stressing the negative effects of selective patent strategies on patent quality.

Second, our findings find that government support for patent-seeking activities is not associated with high-quality patent activity on average. In contrast, at the firm level we find that policy-driven patent behavior is associated with lower patent quality evaluations. Acknowledging that the economy-level and net effects are not known from our methodology, our findings suggest that the market may be a better mechanism for screening patent-related investment and strategies. More research is required to inform how best in this case Chinese decision-makers should weigh the trade-off between patent quantity and quality when seeking to encourage patent seeking via subsidy or political impetus. This will help to avoid patent inflation along the lines of that proposed by Hall and Harhoff (2012). Where governments do offer support for patent-seeking behaviours, our results from the Chinese case suggest that they may be wise to design policies that better prioritize patent structure (the effective combination among invention patents, utility models and design patents) over patent quantity. While we retain general support for the strategy of first increasing patent quantity and then improving the quality, evidence suggests that across the economy as a whole, in China's case firms are already filing a high number of patents. Where incentives are offered, these may better target particular sectors or elements of patent filing, such as writing quality. In China's case, 
despite these the high number of patents being filed, our survey results suggest that patent quality remains low in quality.

A decade ago Zhou and Leydesdorff (2006) drew our attention China's emerging importance as a scientific nation. Understanding patent activity in China, including firmlevel patent-seeking motivations and especially within patent-thicketed industries, is becoming increasingly important to innovators globally. Understanding the operations and decision-making of China's own patent authorities and of the policy makers deciding China's innovation incentives is similarly so. Innovative use of China's Patent Survey data such as that presented herein may help toward these goals.

\section{References}

Arrow, K.J. (1971). The economic implications of learning by doing. In Readings in the Theory of Growth. Palgrave Macmillan UK.

Blind, K., J. Edler, R. Frietsch and U. Schmoch (2006). Motives to patent: Empirical evidence from Germany. Research Policy 35(5), pp. 655-672.

Banerjee,S. and T.Kabiraj(2011). Optimal patent length in a north-south framework: a comment. Singapore Economic Review 56(1), pp.51-59.

Burke, M.P, and M. Reitzig (2007). Measuring patent assessment quality-analyzing the degree and kind of(in) consistency in patent offices' decision making. Research Policy 36(9), pp. 1404-1430.

Cameron, A.C. and P.K. Thrived (2005). Micro-econometrics: Methods and Applications. New York: Cambridge University Press.

Fowler, F. (1995). Improving survey questions: Design and evaluation. Applied social research methods series.

Gambardella, A., D. Harhoff and B. Verspagen (2008). The value of European patents. European Management Review 5(2) pp. 69-84.

Garnaut, R. (2012). Through the Looking Glass: Innovation in China in 20 Years' Time. Australian Economic Review 45(4), pp. 457-462.

Graevenitz, G., S. Wagner and D. Harhoff (2011). How to measure patent thickets-A novel approach, Economics Letters 111(1), pp. 6-9.

Hall, B.H. and D. Harhoff (2012). Recent Research on The Economics of Patents.NBER Working Paper 17773, Cambridge, MA 02138. 
Harabi, N. (1995). Appropriability of technical innovations an empirical analysis. Research Policy 24(6) pp. 981-992.

Harhoff D., B. Hall, G. Graevenitz, K. Hoisl, and S. Wagner (2007). The strategic use of patents and its implications for enterprise and competition policies, Final report for EC Tender No ENTR/05/82,1-307.

Harhoff, D., and M. Reitzig (2004). Determinants of opposition against EPO patent grants - the case of biotechnology and pharmaceuticals. International Journal of Industrial Organization 22(4) pp. 443-480.

Harhoff, D., F. M. Scherer, K. Vopel (2003). Citations family size, opposition and the value of patent rights. Research Policy 32(8), pp. 1343-1363.

Huang, C. (2012). Estimates of the value of patent rights in China. UNU-MERIT Working Paper 2012-004.

Lamping, M., R. Hilty, D. Burk, C.,Correa, and P. Drahos, et al (2014). Declaration on Patent ProtectionRegulatory Sovereignty under TRIPS. Max Planck Institute for Innovation \& Competition Research Paper No. 14-19. http://papers.ssrn.com/sol3/papers.cfm?abstract_id=2500784

Lemley, M.A. and C. Shapiro (2005). Probabilistic Patents. The Journal of Economic Perspectives 19(2) pp. 75-98.

Lerner J. (1994). The importance of patent scope: an empirical analysis. Rand Journal of Economics 25(2), pp. 319-333.

Liegsalz, J. and S. Wagner (2013). Patent examination at the state intellectual property office in China. Research Policy42(2), pp. 552-563.

Li, X.(2009). China's regional innovation capacity in transition: An empirical approach. Research Policy38(2),pp. 338-357.

Long, J.S., Freese, J. (2006). Regression models for categorical dependent variables using stata. College Station, TX:Stata Press.

Mann, R. J.,and M. Underweiser (2012). A new look at patent quality: relating patent prosecution to validity. Journal of Empirical Legal Studies 9(1), pp.1-32.

Merges, R. P. (1999). As many as six impossible patents before breakfast: property rights for business concepts and patent system reform. Berkeley Technology Law Journal 14, pp. 577-615.

Pakes, A. and M. Schankerman (1984). The rate of obsolescence of patents, research gestation lags, and the private rate of return to research resources", In R\&D, Patents and Productivity, The University of Chicago Press.

Palangkaraya, A., E. Webster and P. Jensen (2011). Misclassification between patent offices: evidence from a matched sample of patent applications. Review of Economics \& Statistics 93(3), pp.1063-1075.

Reitzig, M. (2002). Valuing patents and patent portfolios from a corporate perspective: theoretical considerations, applied needs, and future challenges. UNECE Expert Background Paper.

Reitzig, M. (2003). What determines patent value? Insights from the semiconductor industry. Research Policy 32(1) pp.13-26. 
Reitzig M.(2004). Improving patent valuations for management purposes—validating new indicators by analyzing application rationales. Research Policy 33(6)pp.939-957.

Sampat B. (2005). Determinants of patent quality: an empirical analysis. Fifth Annual Roundtable on Engineering Entrepreneurship Research working paper.

Zhang, G., X. Lv, and J. Zhou (2014). Private value of patent right and patent infringement: An empirical study based on patent renewal data of China. China Economic Review 28, 37-54.

Zhang, G.P. and X.D. Chen (2012). The value of invention patents in china: country origin and technology field differences. China Economic Review 23, pp. 357-370.

Zhou, P. and L. Leydesdorff (2006). The emergence of China as a leading nation in science. Research Policy 35(1), pp. 83-104. 
Table 1. Key Variables Definitions and Descriptive Statistics

\begin{tabular}{|c|c|c|c|c|c|c|c|}
\hline Variable Name & Definition & Range & Observations & Mean & Stand dev. & Min & $\max$ \\
\hline GEN & overall quality & $1-5$ & 8441 & 3.42 & 0.75 & 1 & 5 \\
\hline TEC & technical quality & $1-5$ & 8494 & 3.54 & 0.80 & 1 & 5 \\
\hline WRI & writing quality & $1-5$ & 8409 & 3.41 & 0.78 & 1 & 5 \\
\hline STA & right stability & $1-5$ & 8400 & 3.55 & 0.80 & 1 & 5 \\
\hline MAR & market value & $1-5$ & 8388 & 3.30 & 0.90 & 1 & 5 \\
\hline Rd_cost & average $R \& D$ cost & $\begin{array}{c}0 \text { or } 1 \\
(1=\text { higher } \\
\text { than median })\end{array}$ & 7973 & 0.68 & 0.47 & 0 & 1 \\
\hline Totpat & total patent & $1-14114$ & 8670 & 63.06 & 263.9 & 1 & 14114 \\
\hline Invshar & $\begin{array}{l}\text { invent patent } \\
\text { share }\end{array}$ & $0-1$ & 8670 & 0.18 & 0.29 & 0 & 1 \\
\hline market_renew & $\begin{array}{l}\text { patent renew } \\
\text { driven by market }\end{array}$ & 0 or $1(1=$ yes $)$ & 8683 & 0.77 & 0.42 & 0 & 1 \\
\hline fss_app & $\begin{array}{l}\text { no } \\
\text { commercialization } \\
\text { intensity of patent } \\
\text { application }\end{array}$ & $0-1$ & 8619 & 0.57 & 0.26 & 0 & 1 \\
\hline ip_dep & IP department & $0-2$ & 8538 & 1.20 & 0.71 & 0 & 2 \\
\hline Own & Ownership & $1-3$ & 8398 & 1.24 & 0.60 & 1 & 3 \\
\hline Size & Size & $\begin{array}{c}0- \\
1(1=\text { medium } \\
\text { or large })\end{array}$ & 8590 & 0.54 & 0.50 & 0 & 1 \\
\hline Zcqy & IP recognize & 0 or $1(1=$ yes $)$ & 8356 & 0.30 & 0.46 & 0 & 1 \\
\hline Gxqy & high-tech & 0 or $1(1=$ yes $)$ & 8483 & 0.58 & 0.49 & 0 & 1 \\
\hline Ssqy & Listed & 0 or $1(1=y e s)$ & 8512 & 0.11 & 0.31 & 0 & 1 \\
\hline Zyqy & central affiliation & 0 or $1(1=$ yes $)$ & 8513 & 0.074 & 0.26 & 0 & 1 \\
\hline
\end{tabular}

Note: $1-5$ is scaled as"1=low","2=relative low","3=moderate","4=relative high","5=high" respectively for each of overall quality, technical quality, writing quality, right stability and market value. For IP department settings, values $0,1,2$ represent no IP department, informal IP department and formal IP department, respectively. For ownership values 1,2,3 represent domestic firm, Hong Kong and Macao firm and foreign firm, respectively. 
Table 2. Self-reported Patent Quality Distribution (\%)

\begin{tabular}{|c|c|c|c|c|c|}
\hline & $\begin{array}{c}\text { Overall } \\
\text { Quality }\end{array}$ & $\begin{array}{c}\text { Technical } \\
\text { Quality }\end{array}$ & $\begin{array}{c}\text { Writing } \\
\text { Quality }\end{array}$ & $\begin{array}{c}\text { Right } \\
\text { Stability }\end{array}$ & Value \\
\hline Low & 0.9 & 0.9 & 1.1 & 0.8 & 2.7 \\
\hline Relatively low & 6.1 & 5.5 & 7.0 & 5.1 & 13.0 \\
\hline Moderate & 50.7 & 43.4 & 49.9 & 44.9 & 45.5 \\
\hline Relatively high & 35.1 & 39.0 & 34.2 & 37.0 & 29.3 \\
\hline High & 7.1 & 11.3 & 7.6 & 12.2 & 8.9 \\
\hline Observations & 8,479 & 8,532 & 8,446 & 8,437 & 8,425 \\
\hline
\end{tabular}

Table 3. Self-reported Patent Quality Indices Correlation Coefficients

\begin{tabular}{|l|c|c|c|c|}
\hline & $\begin{array}{c}\text { Overall } \\
\text { Quality }\end{array}$ & $\begin{array}{c}\text { Technical } \\
\text { Quality }\end{array}$ & $\begin{array}{c}\text { Writing } \\
\text { Quality }\end{array}$ & Stability \\
\hline Technical Quality & $0.77^{*}$ & 1 & & \\
\hline Writing Quality & $0.71^{*}$ & $0.67^{*}$ & 1 & \\
\hline Right Stability & $0.73^{*}$ & $0.66^{*}$ & $0.64^{*}$ & 1 \\
\hline Market Value & $0.78^{*}$ & $0.62^{*}$ & $0.53^{*}$ & $0.59^{*}$ \\
\hline
\end{tabular}

Note:* pair wise correlation coefficient of 0.05 level significance.

Table 4. Correlation Coefficients: Self-Reported and Hard Patent Data Quality Indices

\begin{tabular}{|l|c|c|c|c|c|}
\hline & $\begin{array}{c}\text { Overall } \\
\text { Quality }\end{array}$ & Quality & Quality & Stability & Value \\
\hline CLAIM & $0.08^{*}$ & $0.09^{*}$ & $0.09^{*}$ & $0.07^{*}$ & $0.06^{*}$ \\
\hline PAGE & $0.11^{*}$ & $0.12^{*}$ & $0.11^{*}$ & $0.11^{*}$ & $0.09^{*}$ \\
\hline DURATION & $0.08^{*}$ & $0.09^{*}$ & $0.07^{*}$ & $0.11^{*}$ & $0.05^{*}$ \\
\hline
\end{tabular}

Note: * A pair-wise correlation coefficient that is significant at the 0.05 significance level. 
Table 5. Determinants of Self-Reported Patent Quality Regression Analysis

\begin{tabular}{|c|c|c|c|c|c|}
\hline & (1) & (2) & (3) & (4) & (5) \\
\hline \multirow[t]{2}{*}{$R \& D$ cost } & $0.372 * * *$ & & & & $0.340 * * *$ \\
\hline & $(0.0291)$ & & & & $(0.0295)$ \\
\hline \multirow[t]{2}{*}{ Total patent } & & $-0.000131 * * *$ & & & $-0.0000861 * *$ \\
\hline & & $(0.0000455)$ & & & $(0.0000415)$ \\
\hline \multirow[t]{2}{*}{ Invention patent share } & & $0.355 * * *$ & & & $0.296 * * *$ \\
\hline & & $(0.0449)$ & & & $(0.0475)$ \\
\hline \multirow[t]{2}{*}{ Market maintenance } & & & $0.316^{* * *}$ & & $0.278 * * *$ \\
\hline & & & $(0.0320)$ & & $(0.0338)$ \\
\hline \multirow[t]{2}{*}{ No commercialization } & & & & $-0.233 * * *$ & $-0.129 * *$ \\
\hline & & & & $(0.0517)$ & $(0.0546)$ \\
\hline \multirow[t]{2}{*}{ IP department(informal) } & $0.189 * * *$ & $0.175 * * *$ & $0.176 * * *$ & $0.178 * * *$ & $0.171 * * *$ \\
\hline & $(0.0408)$ & $(0.0386)$ & $(0.0386)$ & $(0.0386)$ & $(0.0410)$ \\
\hline \multirow[t]{2}{*}{ IP department(formal) } & $0.517 * * *$ & $0.505 * * *$ & $0.487 * * *$ & $0.507 * * *$ & $0.470 * * *$ \\
\hline & $(0.0448)$ & $(0.0421)$ & $(0.0421)$ & $(0.0420)$ & $(0.0454)$ \\
\hline \multirow[t]{2}{*}{ Hong Kong and Macao } & 0.0833 & 0.0866 & 0.0791 & 0.0793 & 0.0704 \\
\hline & $(0.0566)$ & $(0.0527)$ & $(0.0527)$ & $(0.0528)$ & $(0.0565)$ \\
\hline \multirow[t]{2}{*}{ Foreign } & -0.0128 & -0.0193 & -0.00610 & -0.00642 & -0.0172 \\
\hline & $(0.0477)$ & $(0.0446)$ & $(0.0449)$ & $(0.0446)$ & $(0.0479)$ \\
\hline \multirow[t]{2}{*}{ Medium and large } & $-0.139 * * *$ & $-0.119 * * *$ & $-0.125 * * *$ & $-0.125 * * *$ & $-0.129 * * *$ \\
\hline & $(0.0301)$ & $(0.0290)$ & $(0.0289)$ & $(0.0289)$ & $(0.0302)$ \\
\hline \multirow[t]{2}{*}{ IP recognized } & $0.101 * * *$ & $0.140 * * *$ & $0.119 * * *$ & $0.128 * * *$ & $0.0925 * * *$ \\
\hline & $(0.0321)$ & $(0.0308)$ & $(0.0308)$ & $(0.0308)$ & $(0.0323)$ \\
\hline \multirow[t]{2}{*}{ High-tech } & $0.238 * * *$ & $0.266^{* * *}$ & $0.295 * * *$ & $0.294 * * *$ & $0.229 * * *$ \\
\hline & $(0.0301)$ & $(0.0290)$ & $(0.0288)$ & $(0.0288)$ & $(0.0303)$ \\
\hline Listed & $-0.115 * *$ & $-0.118 * * *$ & $-0.121 * * *$ & $-0.116^{* * *}$ & $-0.129 * * *$ \\
\hline
\end{tabular}




\begin{tabular}{|l|c|c|c|c|c|}
\hline & $(0.0449)$ & $(0.0423)$ & $(0.0422)$ & $(0.0422)$ & $(0.0453)$ \\
\hline Central affiliation & $-0.262^{* * *}$ & $-0.276^{* * *}$ & $-0.230^{* * *}$ & $-0.270^{* * *}$ & $-0.207^{* * *}$ \\
\hline & $(0.0529)$ & $(0.0510)$ & $(0.0509)$ & $(0.0509)$ & $(0.0530)$ \\
\hline cut1_cons & $-2.126^{* * *}$ & $-2.253^{* * *}$ & $-2.032^{* * *}$ & $-2.386^{* * *}$ & $-2.040^{* * *}$ \\
\hline & $(0.105)$ & $(0.101)$ & $(0.102)$ & $(0.106)$ & $(0.116)$ \\
\hline cut2_cons & $-1.097^{* * *}$ & $-1.271^{* * *}$ & $-1.045^{* * *}$ & $-1.409^{* * *}$ & $-0.996^{* * *}$ \\
\hline cut3_cons & $(0.0925)$ & $(0.0902)$ & $(0.0921)$ & $(0.0956)$ & $(0.104)$ \\
\hline & $0.716^{* * *}$ & $0.518^{* * *}$ & $0.753^{* * *}$ & $0.376^{* * *}$ & $0.843^{* * *}$ \\
\hline cut4_cons & $(0.0917)$ & $(0.0888)$ & $(0.0914)$ & $(0.0942)$ & $(0.103)$ \\
\hline & $2.051^{* * *}$ & $1.869^{* * *}$ & $2.105^{* * *}$ & $1.722^{* * * *}$ & $2.190^{* * *}$ \\
\hline r2_p & $(0.0947)$ & $(0.0914)$ & $(0.0943)$ & $(0.0963)$ & $(0.106)$ \\
\hline L1 & 0.0513 & 0.0482 & 0.0502 & 0.0456 & 0.0598 \\
\hline N & -7408.2 & -8091.2 & -8085.4 & -8116.2 & -7324.5 \\
\hline
\end{tabular}

Note: Use the ordered probit model. Control province fixed effects; the base group of ownership is the domestic firm; the base group of size is small and micro firm; the base group of IP status is non-IP recognized firm; the base group for listed status is non-listed firm; the base group for affiliation status is non-central government affiliation; the base group for IP department settings is non-IP department. Robust standard errors in parentheses; ${ }^{*} \mathrm{p}<0.1,{ }^{* *} \mathrm{p}<0.05,{ }^{* * *} \mathrm{p}<0.01$ for significance. 
Table 6. Determinants of Self-reported Patent Quality: Quality Structure

\begin{tabular}{|l|c|c|c|c|c|}
\hline & Overall quality & Technical quality & Writing quality & Right stability & Market value \\
\hline R\&D cost & $0.340^{* * *}$ & $0.336^{* * *}$ & $0.207^{* * *}$ & $0.273^{* * *}$ & $0.326^{* * *}$ \\
\hline & $(0.0295)$ & $(0.0292)$ & $(0.0292)$ & $(0.0295)$ & $(0.0285)$ \\
\hline Total patent & $-0.0000861^{* *}$ & $-0.0000958^{* *}$ & 0.0000175 & $-0.0000791^{* *}$ & $-0.000130^{* *}$ \\
\hline & $(0.0000415)$ & $(0.0000438)$ & $(0.0000396)$ & $(0.0000400)$ & $(0.0000507)$ \\
\hline Invention patent share & $0.296^{* * *}$ & $0.407^{* * *}$ & $0.326^{* * *}$ & $0.312^{* * *}$ & $0.145^{* * *}$ \\
\hline Market maintenance & $(0.0475)$ & $(0.0485)$ & $(0.0474)$ & $(0.0478)$ & $(0.0467)$ \\
\hline & $0.278^{* * *}$ & $0.260^{* * *}$ & $0.184^{* * *}$ & $0.167^{* * *}$ & $0.332^{* * *}$ \\
\hline No commercialization & $(0.0338)$ & $(0.0329)$ & $(0.0329)$ & $(0.0331)$ & $(0.0325)$ \\
\hline N2_p & $-0.129^{* *}$ & $-0.161^{* * *}$ & -0.0493 & -0.00638 & $-0.178^{* * *}$ \\
\hline L1 & $(0.0546)$ & $(0.0526)$ & $(0.0525)$ & $(0.0538)$ & $(0.0519)$ \\
\hline & -7324.5 & -7847.5 & -7696.0 & -7811.6 & -8619.9 \\
\hline & 7026 & 7067 & 7000 & 6995 & 6979 \\
\hline
\end{tabular}

Note: Use the ordered probit model. Control province fixed effects; the base group of size is small and micro firm; the base group of IP status is non-IP recognized firm; the base group for listed status is non-listed firm; the base group for affiliation status is non-central government affiliation; the base group for IP department settings is non-IP department. Robust standard errors in parentheses;* $\mathrm{p}<0.1,{ }^{* *} \mathrm{p}<0.05,{ }^{* * *} \mathrm{p}<0.01$ for significance. 
Table 7. Patent Quality Determinants in Low and High Patent Intensity Industries

\begin{tabular}{|c|c|c|c|c|c|}
\hline \multicolumn{6}{|c|}{ A: Low patent intensity industry } \\
\hline & Overall quality & Technical quality & Writing quality & Right stability & Market value \\
\hline \multirow[t]{2}{*}{ R\&D cost } & $0.262 * * *$ & $0.259 * * *$ & $0.214 * * *$ & $0.338 * * *$ & $0.323 * * *$ \\
\hline & $(0.0659)$ & $(0.0632)$ & $(0.0658)$ & $(0.0670)$ & $(0.0641)$ \\
\hline \multirow[t]{2}{*}{ Total patent } & 0.0000600 & 0.0000810 & $0.000223 * *$ & 0.0000375 & -0.00000988 \\
\hline & $(0.000106)$ & $(0.000104)$ & $(0.000103)$ & $(0.000114)$ & $(0.000129)$ \\
\hline \multirow[t]{2}{*}{ Invention patent share } & $0.496 * * *$ & $0.586^{* * *}$ & $0.486^{* * *}$ & $0.361 * * *$ & 0.190 \\
\hline & $(0.130)$ & $(0.133)$ & $(0.134)$ & $(0.129)$ & $(0.131)$ \\
\hline \multirow[t]{2}{*}{ IP department(informal) } & $0.290 * * *$ & $0.320 * * *$ & $0.235 * *$ & $0.312 * * *$ & 0.0741 \\
\hline & $(0.0975)$ & $(0.0960)$ & $(0.0964)$ & $(0.0929)$ & $(0.0893)$ \\
\hline \multirow[t]{2}{*}{ IP department(formal) } & $0.548 * * *$ & $0.536^{* * *}$ & $0.518 * * *$ & $0.654 * * *$ & $0.261 * * *$ \\
\hline & $(0.107)$ & $(0.104)$ & $(0.105)$ & $(0.102)$ & $(0.0986)$ \\
\hline \multirow[t]{2}{*}{ Market maintenance } & $0.220 * * *$ & $0.212^{* * *}$ & $0.144^{*}$ & 0.102 & $0.309 * * *$ \\
\hline & $(0.0771)$ & $(0.0748)$ & $(0.0742)$ & $(0.0751)$ & $(0.0750)$ \\
\hline \multirow[t]{2}{*}{ No commercialization } & -0.0236 & -0.100 & -0.0727 & -0.0507 & -0.121 \\
\hline & $(0.122)$ & $(0.121)$ & $(0.123)$ & $(0.124)$ & $(0.117)$ \\
\hline $\mathrm{r} 2 \_\mathrm{p}$ & 0.0862 & 0.0900 & 0.0744 & 0.0859 & 0.0632 \\
\hline $\mathrm{Ll}$ & -1545.4 & -1673.7 & -1618.9 & -1614.2 & -1805.5 \\
\hline $\mathrm{N}$ & 1538 & 1555 & 1530 & 1527 & 1524 \\
\hline \multicolumn{6}{|c|}{ B: High patent intensity industries } \\
\hline & Overall quality & Technical quality & Writing quality & Right stability & Market value \\
\hline \multirow[t]{2}{*}{ R\&D cost } & $0.254 * * *$ & $0.302 * * *$ & 0.0970 & $0.209 * * *$ & $0.255 * * *$ \\
\hline & $(0.0638)$ & $(0.0648)$ & $(0.0636)$ & $(0.0656)$ & $(0.0629)$ \\
\hline \multirow[t]{2}{*}{ Total patent } & $-0.0000970 * * *$ & $-0.0000843^{*}$ & 0.00000979 & $-0.0000941 * *$ & $-0.000159^{*}$ \\
\hline & $(0.0000370)$ & $(0.0000444)$ & $(0.0000317)$ & $(0.0000450)$ & $(0.0000868)$ \\
\hline \multirow[t]{2}{*}{ Invention patent share } & $0.225 * *$ & $0.251 * *$ & $0.273 * *$ & 0.149 & 0.178 \\
\hline & $(0.111)$ & $(0.112)$ & $(0.111)$ & $(0.110)$ & $(0.109)$ \\
\hline \multirow[t]{2}{*}{ Market maintenance } & $0.334 * * *$ & $0.303 * * *$ & $0.203 * * *$ & $0.168 * *$ & $0.327 * * *$ \\
\hline & $(0.0722)$ & $(0.0719)$ & $(0.0710)$ & $(0.0698)$ & $(0.0704)$ \\
\hline No commercialization & -0.173 & -0.0618 & 0.0204 & 0.0922 & $-0.268 * *$ \\
\hline
\end{tabular}




\begin{tabular}{|l|c|c|c|c|c|}
\hline & $(0.125)$ & $(0.120)$ & $(0.118)$ & $(0.122)$ & $(0.120)$ \\
\hline $\mathrm{r} 2 \_\mathrm{p}$ & 0.0822 & 0.0617 & 0.0493 & 0.0539 & 0.0554 \\
\hline $\mathrm{L} 1$ & -1574.4 & -1721.9 & -1697.3 & -1753.8 & -1912.8 \\
\hline $\mathrm{N}$ & 1614 & 1619 & 1608 & 1608 & 1597 \\
\hline
\end{tabular}

Note: Use the ordered probit model. Control province fixed effects and industry fixed effect; the base group of ownership is the domestic firm; the base group of size is small and micro firm; the base group of IP status is non-IP recognized firm; the base group for listed status is non-listed firm; the base group for affiliation status is non-central government affiliation; the base group for IP department settings is non-IP department. Robust standard errors in parentheses; ${ }^{*} \mathrm{p}<0.1,{ }^{* *} \mathrm{p}<0.05,{ }^{* * *} \mathrm{p}<0.01$ for significance. 